\title{
First Experience of Transfer with Impella 5.0 Over the Long Distance in Japan
}

\author{
Masakazu Hori, ${ }^{1}$ MD, Makiko Nakamura, ${ }^{1}$ MD, Masaki Nakagaito, ${ }^{1}$ MD and Koichiro Kinugawa, ${ }^{1}$ MD
}

\begin{abstract}
Summary
We recently experienced a 43-year-old man with dilated cardiomyopathy transported under the Impella support to a high-volume left ventricular assist device (LVAD) center. Stabilized hemodynamics with the Impella and firm fixation of the device were important for safe transportation of the patient.
\end{abstract}

(Int Heart J 2019; 60: 1219-1221)

Key words: Ventricular assist device, Cardiogenic shock, Bridge to transplantation, Heart transplantation

I mplantable left ventricular assist device (LVAD) is approved only as a bridge to transplantation in Japan, and patients in cardiogenic shock or with deteriorating hemodynamics requiring mechanical circulatory support (MCS) have to be evaluated for eligibility for heart transplantation (HTx) before determination of the indication of implantable LVAD. Impella is a catheter-based transaortic microaxial pump which has been approved in Japan since September 2017. Before Impella became available, we had to open the chest and paracorporeal LVAD implantation took place which had high operative invasions and more frequent complications such as infection or stroke, and occasionally required right ventricular assist device implantation in the patients with cardiogenic shock who had not yet been judged as being eligible for HTx. ${ }^{1)}$ Impella can be inserted percutaneously and directly unloads the left ventricle, and it has been reported as a useful temporary MCS for bridging to HTx or durable LVAD. ${ }^{2,3)}$ Successful experiences of transportation with Impella over long distance have already been reported in Canada or the US, ${ }^{4,5)}$ but never to date in Japan. Here, we present the first case of a patient who was safely transported with Impella 5.0 over $\sim 450 \mathrm{~km}$ in Japan.

\section{Case Report}

A 43-year-old man was diagnosed with non-ischemic dilated cardiomyopathy at the age of 29 and had received optimal guideline directed medical therapy at the hospital previous to our one. Low peak oxygen consumption $(9.8$ $\mathrm{mL} / \mathrm{minute} / \mathrm{kg}$ ) was reported in the last year. In September 2018, he was hospitalized with decompensated heart failure for the fourth time and referred to University of Toyama hospital.

He had a standard figure of Japanese men $(174 \mathrm{~cm} /$ $68 \mathrm{~kg}$ ). On admission, his blood pressure was 78/50
$\mathrm{mmHg}$ and chest X-ray showed pulmonary congestion. Transthoracic echocardiography showed reduced left ventricular ejection fraction of $20 \%$ and end-diastolic left ventricular diameter of $80 \mathrm{~mm}$. Levels of B-type natriuretic peptide (BNP) $(1301 \mathrm{pg} / \mathrm{mL})$ and serum creatinine $(1.21 \mathrm{mg} / \mathrm{dL})$ were elevated. Right heart catheterization revealed high pulmonary artery wedge pressure $(22 \mathrm{mmHg})$ with low cardiac index $\left(1.4 \mathrm{~L} /\right.$ minute $\left./ \mathrm{m}^{2}\right)$. Since total bilirubin level was increased to $2.8 \mathrm{mg} / \mathrm{dL}$ within several days despite the incremental dose of intravenous inotropes, we inserted Impella 5.0 on the sixth day (Figure 1). We chose his right axillary artery for the access site because we anticipated long support duration until HTx listing as well as future transfer to a LVAD center. Pump flow was $\sim 4.5 \mathrm{~L} /$ minute with P8 level under continuous administration of dobutamine (4 $\mu \mathrm{g} / \mathrm{kg} /$ minute) and milrinone $(0.2 \mu \mathrm{g} / \mathrm{kg} /$ minute $)$ in consideration of his right ventricular impairment. Thereafter, we started the evaluation of eligibility for HTx that eventually took more than a month before listing. At the same time, we initiated a discussion for his transfer plan to a high-volume LVAD center located in the Tokyo Metropolitan area, which was a hub institute for our hospital. His BNP level was declined to $136 \mathrm{pg} / \mathrm{mL}$ with normal levels of serum creatinine and total bilirubin on the thirty-fourth day (Figure 1). By that time, he was able to hold the upright position by rehabilitation, and could easily be transferred to a wheelchair with little help. On the thirty-fifth day, we transported him using a large ambulance car run by a private company. Members of our transport team consisted of a cardiologist, a coronary care unit nurse, and a perfusionist. During transportation, the Impella catheter was fixed on his right chest (Figure 2A) and the controller was fastened tightly on the stand at his feet (Figure $2 \mathrm{~B}$ and C). We brought a portable echocardiograph in case of repositioning of the Impella catheter. Aortic pressure wave

From the ${ }^{1}$ Second Department of Internal Medicine, University of Toyama, Toyama, Japan.

Address for correspondence: Makiko Nakamura, MD, Second Department of Internal Medicine, University of Toyama, 2630 Sugitani, Toyama 930-0194, Japan. E-mail: nakamura@med.u-toyama.ac.jp

Received for publication January 19, 2019. Revised and accepted April 5, 2019.

Released in advance online on J-STAGE September 4, 2019.

doi: 10.1536/ihj.19-038

All rights reserved by the International Heart Journal Association. 


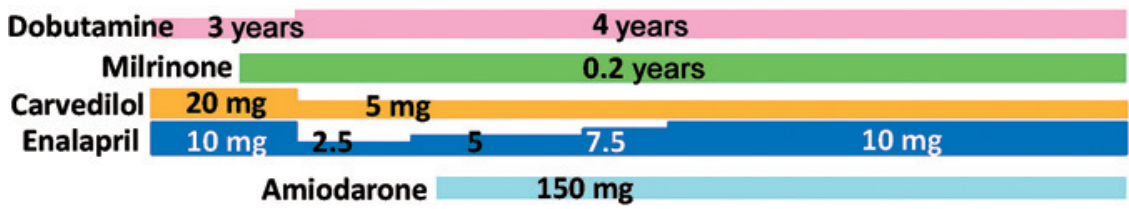

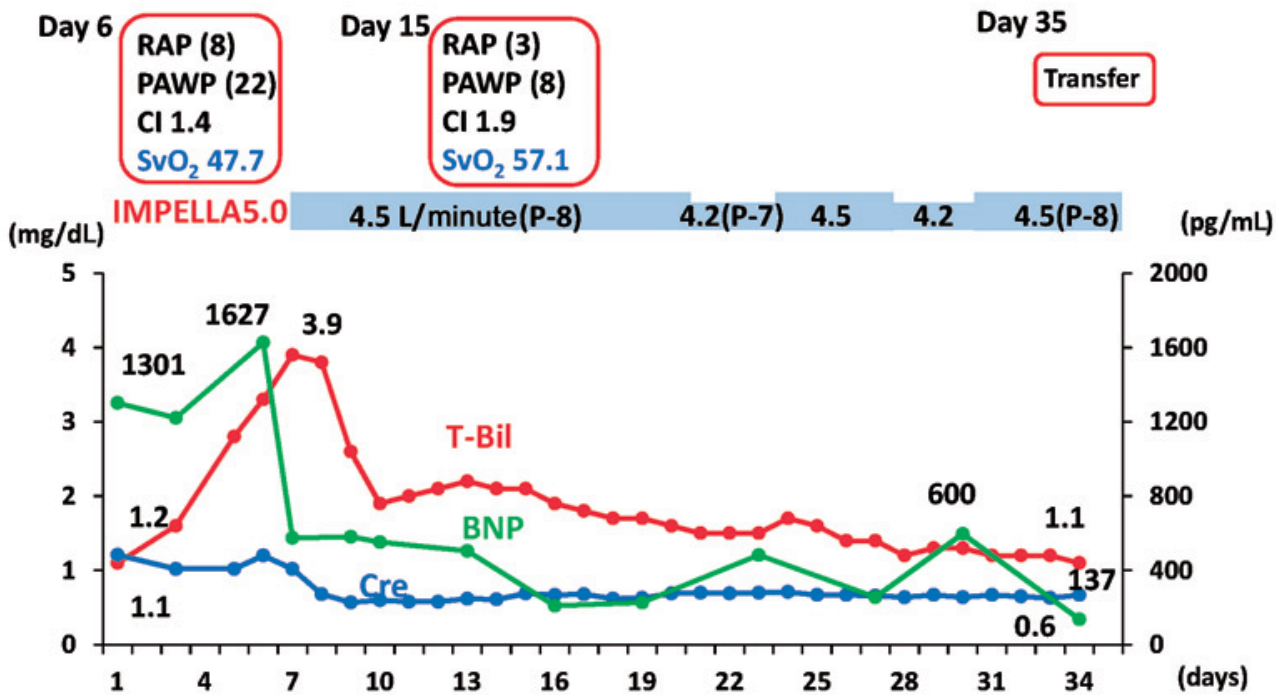

Figure 1. This figure shows the clinical course of the patient's serum creatinine, total bilirubin, and B-type natriuretic peptide levels after Impella 5.0 insertion until transfer. The amount of administered drugs and support level of Impella are also shown. T-Bil indicates total bilirubin; Cre, serum creatinine; BNP, B-type natriuretic peptide; RAP, right atrial pressure; PAWP, pulmonary artery wedge pressure; $\mathrm{CI}$, cardiac index; and $\mathrm{SvO}_{2}$, mixed venous oxygen saturation
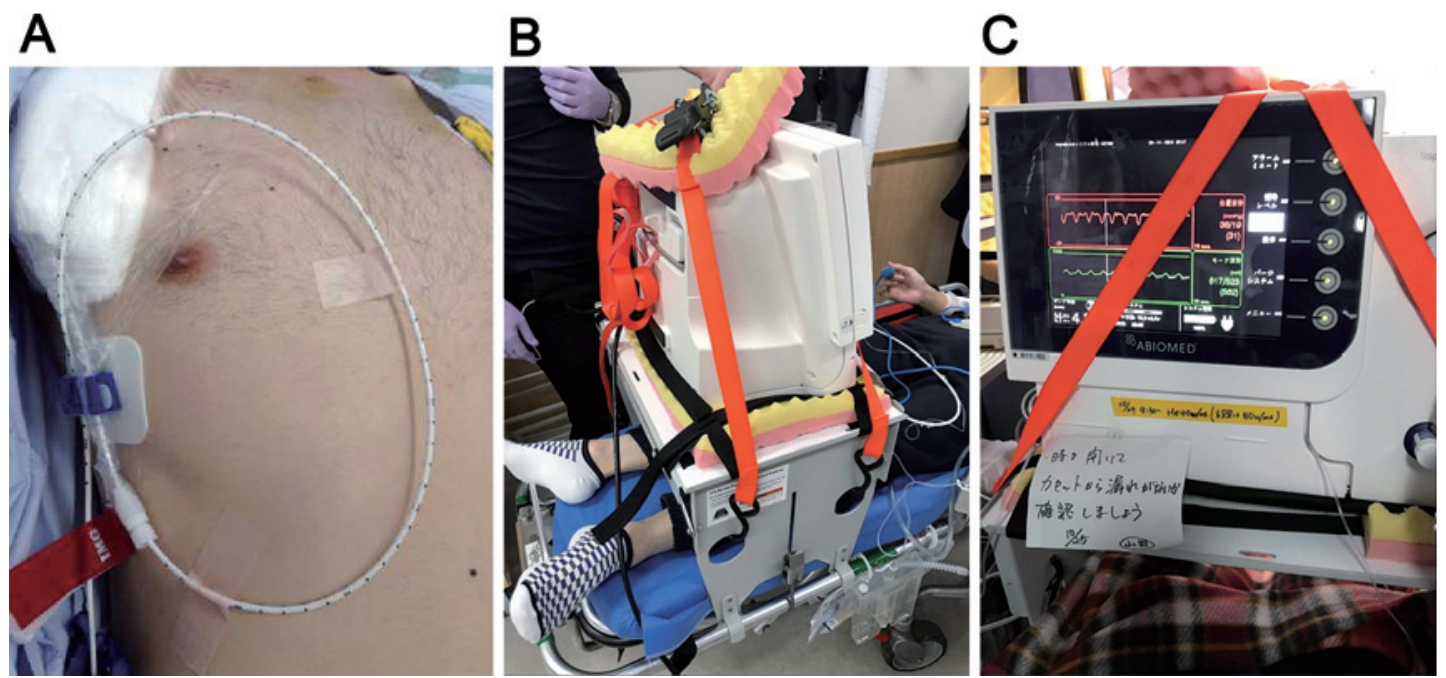

Figure 2. The fixation of the Impella catheter and the controller device during transport. The fixed catheter on his right chest (A) and the fastened controller (B: side view; $\mathbf{C}$ : front view) are shown. Impella catheter was fixed with tubing anchor and the whole area was covered by a transparent dressing tape (not shown in this Figure). The controller was placed on a stand installed at the feet of the patient and fixed with a belt in order not to move. Pressure sores prevention mattress (SOFT NURSE ${ }^{\circledR}$ ) was cut into a U shape and laid on the underside of the controller so as to interfere with vibration and not block the vent holes on the bottom and back of the controller. Two fixed belts were applied diagonally so that the monitor screen on the front of the controller could be observed.

form, motor wave form, and purge flow rate were carefully monitored. We decided to skip his breakfast and lunch, but we gave him sufficient fluid intravenously in place of meals. We arrived at the hub hospital without any trouble after 6.5-hour drive. His HTx eligibility was approved by the committee of the Japanese Circulation Soci- 
ety on the thirty-sixth day, and HeartMate II was implanted on the same day. He was discharged two months after the LVAD surgery and his condition was one of well-being on the outpatient basis as of January 2019.

\section{Discussion}

Our experience of transfer under the Impella support is the first case in Japan. Similar to our patient, a Canadian group reported a successful case of interprovincial spoke-to-hub transport under Impella 5.0. ${ }^{4)}$ On the other hand, left ventricular perforation during transport due to the device migration has been reported. ${ }^{6}$ To avoid displacement, malposition, or any adverse event during transfer, appropriate travel planning and strict preventive measures are warranted. In the above two cases, Impella was inserted from femoral artery, but right axillary artery might be a better access site in terms of the stability of the catheter position. We also minutely adjusted the catheter position and fixed the entire system firmly before departure. As a result, we did not need to adjust the catheter position throughout transportation. Kang, et al. in their study reported a case series of the Impella transportation in the US mountainous area. ${ }^{5)}$ The transport distance was $585 \pm 264$ (range: 238-1128) km, and they used fixedwing aircrafts with transfer time of $170 \pm 29$ minutes. Travel from Toyama to Tokyo also required crossing of the high mountains, but we transported similar distance by car. We did not choose the Prefectural fire helicopter since it was vulnerable to the mountain weather and was not equipped with AC power supply. Through the Aero Medical Evacuation Squadron of the Japanese Air Force, an aircraft tougher to the weather was available that had better equipment including $\mathrm{AC}$ power, but multiple transfers were necessary to and from hospitals and airports. Time for car transportation was much longer, but had an advantage of door-to-door connection that only needed a single fixation of the system at departure. Transfer of longer time might need more stable hemodynamics and rehabilitated status, which was attained in this case by extended support by Impella for a month.

In summary, we experienced the first transfer under the Impella support over long distance in Japan. Wellconducted initial plans and meticulous attention during transportation were keys to the success of travel with Impella. Above all, fixation of the whole system was crucial for the safety, and it might be better to minimize the number of changing vehicles rather than shorten the total time of transfer.

\section{Disclosure}

Conflicts of interest: None.

\section{References}

1. Nitta D, Kinugawa K, Imamura T, et al. A useful scoring system for predicting right ventricular assist device requirement among patients with a paracorporeal left ventricular assist device. Int Heart J 2018; 59: 983-90.

2. Lima B, Kale P, Gonzalez-Stawinski GV, Kuiper JJ, Carey S, Hall SA. Effectiveness and safety of the impella 5.0 as a bridge to cardiac transplantation or durable left ventricular assist device. Am J Cardiol 2016; 117: 1622-8.

3. Hall SA, Uriel N, Carey SA, et al. Use of a percutaneous temporary circulatory support device as a bridge to decision during acute decompensation of advanced heart failure. J Heart Lung Transplant 2018; 37: 100-6.

4. Guirgis M, Kumar K, Zieroth S, Philipp R, Menkis AH, Freed $\mathrm{DH}$. Interprovincial spoke-to-hub transport using the Impella Recover LP 5.0 left ventricular assist device as a bridge to longterm circulatory support. Can J Cardiol 2010; 26: 320-2.

5. Kang TS, Ko BS, Drakos SG, et al. Safety of long-distance transfers of patients on acute mechanical circulatory support. J Surg Res 2018; 224: 18-22.

6. Peritz DC, Linstroth L, Selzman CH, Gilbert EM. Left ventricular perforation after Impella ${ }^{\circledR}$ placement in a patient with cardiogenic shock. Catheter Cardiovasc Interv 2018; 91: 894-6. 